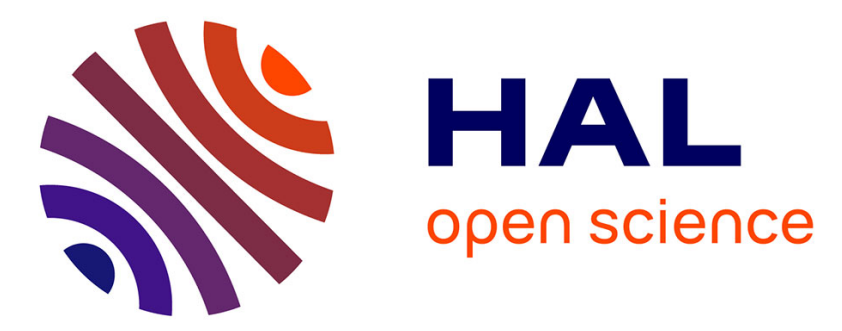

\title{
Development of an Assistance Environment for Tutors Based on a Co-Adaptive Design Approach
}

\author{
Elise Lavoué, Sébastien George, Patrick Prévôt
}

\section{To cite this version:}

Elise Lavoué, Sébastien George, Patrick Prévôt. Development of an Assistance Environment for Tutors Based on a Co-Adaptive Design Approach. Behaviour and Information Technology, 2012, 31 (2), pp.127-141. hal-00652620

\section{HAL Id: hal-00652620 \\ https://hal.science/hal-00652620}

Submitted on 15 Dec 2011

HAL is a multi-disciplinary open access archive for the deposit and dissemination of scientific research documents, whether they are published or not. The documents may come from teaching and research institutions in France or abroad, or from public or private research centers.
L'archive ouverte pluridisciplinaire HAL, est destinée au dépôt et à la diffusion de documents scientifiques de niveau recherche, publiés ou non, émanant des établissements d'enseignement et de recherche français ou étrangers, des laboratoires publics ou privés. 


\title{
Development of an Assistance Environment for Tutors Based on a Co-Adaptive Design Approach
}

\author{
Élise Lavoué ${ }^{\mathrm{a}, \mathrm{b}}$ *, Sébastien George ${ }^{\mathrm{a}}$ and Patrick Prévôt ${ }^{\mathrm{b}}$ \\ Université de Lyon \\ ${ }^{a}$ INSA-Lyon, LIESP, F-69621, Villeurbanne,France \\ ${ }^{b}$ Université Jean Moulin Lyon 3, IAE, Centre de recherche MAGELLAN, Groupe SICOMOR, Lyon, France
}

*Corresponding author.

E-mail addresses: Elise.Lavoue@univ-lyon3.fr (É. Lavoué), Sebastien.George@insa-lyon.fr (S. George), Patrick.Prevot@,insa-lyon.fr (P. Prévôt).

\begin{abstract}
In this paper, we present a co-adaptive design approach named TE-Cap (Tutoring Experience Capitalisation) that we applied for the development of an assistance environment for tutors. Since tasks assigned to tutors in educational contexts are not well defined, we are developing an environment which responds to needs which are not precisely identified or not expressed by these users. Our approach rests on three development cycles which aim at gradually clarifying and refining users' needs and expectations which we translate into computing functionalities. Each cycle is composed of three steps that allow the use of prototypes developed with regard, on the one hand, to theories of users' activities and, on the other hand, to the needs that we have identified to be observed. We finally obtain a stable typology of users' needs and expectations upon which we base the development of the computer environment. We illustrate the two first cycles of this iterative and co-adaptive approach during the development of TE-Cap. We then discuss the difficulties raised by this type of approach.
\end{abstract}

Keywords: Co-adaptive Design Approach; Assistance System for Tutors; Communities of Practice; Experiences Sharing; Knowledge Management; Needs Analysis.

\section{Introduction and research issues}

With the changes due to the prominent part played by Information and

Communication Technologies (ICT) in education, a new role for the tutor has

appeared. While the instructional designers design the educational content, the tutors

monitor the students' learning activities. In the literature tutors within this field are

named according to their functions: moderator, facilitator, online tutor, online

moderator, e-moderator, coach, distance education tutor, e-tutor etc. The problem is

that the role of tutor is still not well defined. We think that there is not one single type

of tutor but rather that tutors define themselves with regard to the functions they have

to fulfil. Their main functions are not the same dependant upon whether the 
communications are mediated or not, whether the learning tasks are collaborative or individual and whether the course takes place in punctual sessions or as a long lasting activity. This results in numerous difficulties and problems, more or less dominant according to the presence of these various factors. For example, during mediated communications tutors will have particular difficulties relating to appropriation of tools and technical problems, whereas in distance training the difficulties will be bound more to issues such as lack of learner motivation and autonomy. Also, the functions of the tutor are more or less important, depending on the context of a course. Nevertheless, there are some general functions assigned to tutors that we have synthesised. We group them as being: assessor, intellectual catalyst, moderator of interactions, psychological and emotional support, facilitator of learning, technical support, pedagogical architect (Garrot et al. 2009). We base our work on the hypothesis that, even if tutors work in different contexts, they encounter similar problems and difficulties. We mainly identify the lack of training; the lack of tracking of their practice; the lack of a well defined professional identity and the lack of recommendations which would allow them to properly assume their role. We are interested in tutoring as a general activity, with the aim of helping tutors to assume their functions and to provide answers to most of their needs. Our research aims at developing an innovative assistance environment for tutors to improve their efficiency and the way they work.

The problem which is challenging us is the development of a system to optimise some tasks which are badly identified, even today. In this paper, we propose a co-adaptive design approach. This approach aims at developing a platform which answers to tutors' needs in terms of help or assistance, independently of the institution to which they belong. It implies the formalisation of needs which are not identified or 
at least not expressed by these users. Since tasks assigned to tutors vary according to institutions, our objective is not to develop an environment that would optimise particular tasks, to which recognisable needs correspond. Our objective, rather, is to understand tutors' activities in qualitative and quantitative terms in order to generate new ideas of conception and to innovate. Like Delozanne et al. (2002) we consider that, when research concerns the conception of innovative software, it becomes extremely difficult to anticipate users' activity with a system which does not exist and which does not yet present an equivalent. The final aim of our system is to support an emerging helping process between tutors that cannot be well defined a priori. That is why our experimental approach consists of making the users become aware of their needs in order to provoke reactions and make them express these implicit needs. This approach also allows us to interpret users' implicit needs in regard to existing theories.

In this paper, we first explain the global co-adaptive approach we propose and the participatory design methods that it uses. Then, we detail the three development cycles and the steps that comprise each one. We illustrate the two first cycles with the case of the TE-Cap platform (Tutoring Experience Capitalisation): an environment to support tutors. Finally, we conclude and present some future directions of our research.

\section{A co-adaptive design approach}

\subsection{Proposed approach}

We propose an experimental approach based on an iterative process. According to Mackay and Fayard (1997) for triangulation across disciplines, each cycle should be composed of three steps: theory, design of artefacts and observation (see Figure 1). Indeed, when the activities are poorly identified, the literature is a resource rich in 
propositions for new prototypes. That is why our approach uses the design of prototypes based on techniques drawn from a variety of research and from several disciplines. This approach allows us on the one hand to understand the users' activities and to anticipate the use of the system and, on the other hand, to develop prototypes with regard to the observed use.

The specifications of users' needs and expectations are at the centre of the design process because it is necessary to 'create', to define and to refine them, in order to develop the technology based on this evolution. The iterative process aims at clarifying users' needs by experimenting on the ground using a prototype based on needs as they emerge. The process is composed of three development cycles: (1) identification of the basic users' needs (see §3), (2) specification of the platform (see $\S 4)$ and (3) adequacy of the platform for users' activities (see §5). Each cycle is composed of several steps:

a. Developing a prototype based on the users' needs and the defined specifications. The needs are identified and refined according to theories on user activities which allow interpreting implicit needs. The specifications of the prototype are based on these needs. We based our study on the literature on tutoring and on the concept of Communities of Practice (cf. §3.3).

b. Observing the use of the prototype by the users during authentic activities. The prototype makes the users react to and express these reactions to their practice. We can gather information by collecting tracks of use, by sending questionnaires to tutors and by making usability tests.

c. Interpreting the results of the observation with regard to theories on user activities. These theories provide a part of the interpretation of our users' behaviour with the 
prototype. This step aims at clarifying user needs and expectations, on which the following development cycle is based.

This approach has three main goals:

- To clarify and to gradually refine users' needs and expectations. We make users become aware of their needs and express them. Then we translate these needs into characteristics and specifications for a platform, with the help of existing theories. In every cycle, we increased the panel of users: from a smaller group of users for the first cycle up to a community for the last cycle. This allowed the results of first pilot study to be processed in detail and thus enabled us to refine the specifications of the system. The use by a community allows the testing of the final system on a larger scale, whilst limiting the risks, in particular computing risks. We finally obtained stable specifications upon which we based the development of the final platform.

- To obtain and extend and develop the vocabulary used by users, in order to design a human-computer interface adapted to users' practices.

- To gradually familiarise users (the users of the previous cycle and the new ones) with the proposed environment and to integrate it into their practice. Involving users in each development cycle allowed the creation of a need for this tool and of an interest in using it.

\section{Figure 1}

In next section we study the existing participatory design methods so as to situate the proposed approach and to justify the choice of the methods on which this approach is based. 


\subsection{Participatory design: an overview}

For the development of our system, we have adopted an experimental, user-centred approach based on existing participatory design methods. We chose two methods according to two factors proposed by Kuhn and Muller (1993) to classify participatory design practices:

- Who participates with whom in what? (This relates to the role of the designers in the users' world and of the users directly in the design activity).

- Time taken during the development life cycle or iteration.

Concerning participation, several approaches bring designers to participate in users' activities so as to elaborate models of their work. Contextual design (Holtzblatt and Beyer 1993) is a widely used approach based on a well-defined sequence of activities by the design team. The first step consists of a contextual inquiry which aims to incorporate valid, useful data on users' work in the engineering process. Its goals are similar to those of semi-structured interviewing (Wood 1997): to understand work in enough detail to know what the system must do to support it well, and to identify what innovations will streamline the work. The following steps consist of representing in the form of diagrams and models the users' activities: their context, the roles of the users and the sequencing. But formal models are often slow and expensive to develop and difficult to understand (Jarke 1999). Furthermore, they emphasise the functions and the features of the system rather than what it is possible to do with the system and the consequences which ensue from it. Jarke (1999) highlights the use of scenarios as a key artefact in systems engineering. A scenario describes a possible set of events that might reasonably take place, taking into account current problems, possible occurrences, and assumptions relating to these occurrences, action opportunities and risks. 
These user-centred approaches lead to the conception of models or scenarios of users' work and practices in order to design a suited product. But they do not allow for the development of the product over time and with its use. Our approach, however, rests on the assertion that the use of technology is co-adaptive (Mackay and Fayard 1997) in the sense that it modifies the working customs and users' expectations. Users adapt the technology to their needs and these needs evolve at the same time. That is why we think it is essential that designers and users collaborate, in order to meet their needs as they evolve through the use of the system. The evolution of the system rests on the specifications of the users' needs which evolve and become clearer in every design cycle.

For that purpose, we pay particular attention to two methods among those presented in Muller's (2003) survey of the methods, techniques, and practices in Participatory Design (PD) that can lead to hybrid experiences - that is, practices that take place neither in the workers' domain, nor in the software professionals' domain, but 'in an 'in-between' region that shares attributes of both the workers' space and the software professionals' space". These two methods are:

- The use of a low-tech prototype as the medium to lead users to express themselves about what they need in their practice. The end-users are often being asked to think about technologies or applications that they have not previously experienced. Muller (2003) claims that a low-tech prototyping approach enhanced communication and understanding through grounding discussions in concrete artefacts and also enhanced the incorporation of new and emergent ideas through the ability of participants to express their ideas directly via the low-tech materials.

- Evolutionary prototyping: this approach led to enhanced communication with endusers, improved incorporation of end-user insights into the prototypes and stronger 
collective ownership. The framework STEPS (Floyd 1993) is a methodology to develop interactive application systems by applying evolutionary prototyping. STEPS considers the anticipation of use to be an inherent part of the development. Evolution refers to the emergence of insights into the functionality and the potential use of the software. Participation refers to the strategy of mutual learning. Software requirements are related to the context of user work processes as a whole, and the software system itself gives rise to new requirements. Each cycle is composed of version production, application and revision.

We apply these methods in our framework, each method depending on the time during the development cycle (Kuhn and Muller 1993). In the following sections, we detail the development cycles, illustrated by the example of the development of TE-Cap (Tutoring Experience Capitalisation) environment.

\section{Identification of the basic user needs}

\subsection{Steps of the first development cycle}

The first development cycle aims at identifying users' needs and expectations by interviewing users. These interviews are based on a literature study, which helped us to define a priori needs and to develop a low-tech prototype of an assistance system. The detailed steps are set out in the following:

a. Doing a survey of the literature relating to users' activities and experiences: from this study we can identify users' roles and tasks and deduce some of their needs. This first study led to the design of a low-tech prototype which answers to these needs. It consists of a proposal for a human-computer interface and functionalities (tools offered on the system we want to develop).

b. Conducting interviews composed of two phases with several users: 
- Semi-structured interviewing: this approach gives some degree of freedom to users that allows them to speak about their practices and to express their needs. The interviews are transcribed in order to be able to analyse their content and to determine the vocabulary used by the users when they talk about their practices. This is essential for the design of an environment adapted to users' practices. Indeed, we have noticed that many environments are not used because users do not recognise themselves in the vocabulary used for the interface.

- Presentation of the low-tech prototype in order to provoke reactions with respect to the functionalities and interface proposed. We have already detailed in a previous part the benefits of this approach in terms of communication and understanding through grounding discussions in concrete artefacts and incorporation of new and emergent ideas through the ability of participants to express their ideas directly via the low-tech prototype.

c. Analysing our interview transcriptions in order to determine explicit and implicit needs. At this step, we refer to the literature to examine whether any existing theories can help to make implicit needs emerge or help in the interpretation of some needs to deduce more general or more specific needs.

This first development cycle aims at identifying users' activities and practices. The low-tech prototype presented during the interviews acts as a catalyst, precipitating users to tell about their practices and their requirements to support them. By analysing interviews, we begin to draw a first typology of the users' needs (explicit and implicit). But these are not clearly expressed and therefore it is necessary to propose to users a software prototype to use in their practice. 


\subsection{Identification of the tutors' needs}

\subsubsection{The low-tech prototype}

Our first work was based on a literature survey on tutors' roles (Garrot et al. 2009).

Using this analysis of tutors' activities and tasks, we first determined general needs for tutors in terms of functionalities in order to make them interact and help each other:

- To interact with other tutors about experiences and to determine 'good practices'.

- To refer to expert in particular fields of competency (technical, subject matter...).

- To relate and store experiences.

- To record documents, useful links and other resources.

- To retrieve contextual experiences stored as knowledge.

In regard to the tutors' activities and to the general needs identified, we designed a prototype of an assistance system based on the roles that we assigned to tutors. The prototype proposes:

- Communication tools (email and a forum) in order to allow tutors to interact.

- An interface to store and retrieve tutors' experiences in a database.

Figure 2 illustrates an interface used to store experiences bound to a particular type of pedagogical activity: problem solving activities. The interface takes the shape of a matrix. When accessing the interface, tutors could store experiences according to a function or a specific phase of the course. The first row corresponds to several phases of a course, which are parameterised activities. When accessing the matrix for the first time the tutor determines the parameters (illustrated in a cell) of each particular activity in his/her course:

- Individual $\theta$ or collective $\because$ activity.

- At distance $\square \leftrightarrow \square$ or in presence $\theta \rightarrow \rightarrow$ activity. 
- Synchronous $Q$ or asynchronous $\bigotimes$ activity.

\section{Figure 2}

The first column of the matrix lists the different tutor functions which we presented in section 3.2.2. Figure 2 illustrates a case study which has four activities. The tutor can click on different cells to store or search an experience. For example:

- (1) is a cell in the intersection of a column and a row. The tutor accesses experiences which correspond to the function of motivational support and the second phase of the case study (cause searching).

- (2) is a cell in the first column. The tutor accesses all the experiences linked to the motivational support function.

- (3) is a cell in the first row. The tutor accesses all the experiences related to the second phase.

The number in each cell indicates the number of experiences which correspond to a specific function and an activity type. The darker the colour of the cell, the more stored experiences it has. So, with this matrix, tutors can store and access very quickly the experiences which concern them.

\subsubsection{Results and analysis of interviews}

We then conducted seven interviews with tutors from different institutions so as to identify their explicit and implicit needs. These interviews were composed of two phases: (1) semi-structured interviews and (2) the presentation of the low-tech prototype. The presentation of this prototype aroused reactions and it was easier for the tutors to express their needs by saying what they did not need rather than what they needed. We think that it was necessary to have some support to enable them to express their needs. We first present the results in terms of technology, then those relating to the identification of the tutors' needs. 


\subsubsection{Functionalities for a system}

Concerning the interface in the form of a matrix, several tutors raised the difficulty of classifying an experience in a cell. We notice that they felt forced to have to fill in all the cells, but they did not think they could a priori put a lot of information in them: "I do not see what I could put inside in fact." More precisely, the division of the scenario into activities seems interesting because it requires less reflection about the situation. In fact, it reduces the complexity of the scenario and so it does not require a global approach to the whole scenario. But the division into several tutor functions is not relevant because tutors are not aware of all the functions that constitute their role, particularly in the context of an activity such as in the scenario they were given here. It requires too much reflection on their day-to-day practice (it is not easy to know if an experience concerns a precise tutor function). Furthermore, it does not really hold much interest for tutors to know which role they are playing. To conclude, it seems to be easier to find information than to formulate an experience corresponding to a cell. The matrix which obliges tutors to choose a cell is too precise. We have to give them more degrees of freedom.

The tutors did not seem to be satisfied with the notion of only two factors which make tutoring vary, namely 'tutoring and activity'. These factors do not answer to all the problems encountered by them. For example, tutors have problems to solve concerning particular types of learner (for instance, someone who has difficulty relating to the group) or relating to the institution to which they belong. We thus questioned our view of tutoring according to these two factors. We tried to see all the subjects in relation to the practice of tutoring. As a result, we developed a new model of the factors in relation to the practice of tutoring; one based on the vocabulary used by the tutors during interviews. This model was adapted to use in the interface of the TE-Cap platform developed in the second life-cycle (see Figure 3). 


\subsubsection{Tutors' needs}

We conducted seven interviews with tutors with different backgrounds: two tutors from the FORSE campus of Lyon (educational sciences), one tutor from the FORSE campus of Rouen (educational sciences), two tutors from the VCiel campus (computer science), one tutor from DESS UTICEF (use of ICT in education and training) and one adult educator from GRETA of Lyon (training to set-up blended learning). Nineteen questions guided the course of these interviews which lasted approximately one hour. The subjects addressed were:

- What are the experiences and the initial skills of the tutors?

- What training was given to them? Which benefits and difficulties did training bring?

- How do the tutors build their practice? Do they exchange practical experience with others?

- What is the nature of the interactions between tutors? What are the interesting aspects, the difficulties?

The questions we asked aimed at getting to know about their practices, deducing their implicit needs and identifying the vocabulary used in their practice. The analysis of the interviews was made in a qualitative way, without the use of computing tools other the transcription of the interviews. We made a synthesis of the tutors' needs from our study of the literature dealing with tutoring and this study on the ground. We identified four major categories of needs. For each of these categories we studied the answers on offer at present so as to highlight the lacks:

- Need for help in monitoring learners' activities: in most educational institutions instructional designers have Course Management Systems such as Blackboard (West et al. 2007), which allow them to make the content of their course 
accessible at distance, sometimes with high level interactivity, for instance with tutorial conversation systems (Song et al. 2004). But these systems provide tutors with little specific functionality. Most of these systems offer standard communication tools such as forums (George 2006), chat or blogs in order to encourage tutors to interact together and with students (Stahl et al. 2007). In some cases these environments propose tools to visualise traces of student activities so as to help tutors to monitor them (Després 2003, Laperrousaz et al. 2005). These environments and tools can be useful when they are adopted by tutors (Galanouli et al. 2004, West et al. 2007), but are not sufficient. It seems useless to provide information about students to tutors if they do not know what their work involves.

- Need for formal tutor training to become a tutor: McPherson and Nunes (2004) highlight the fact that there is no training which attempts to help tutors to develop the skills that are required to manage and facilitate online learning such as: matter expertise, technical, pedagogical, information and communication skills. This point is also raised by Godinet and Caron (2003) within the framework of the FORSE campus. They highlight the fact that tutors receive neither specific training nor instructions; the tutor training is usually carried out through informal exchanges between peers with mutualisation of experiences, requests for assistance, and advice on joint positions to adopt with regard to common situations. Class and Schneider (2004) present the setting up of a Structure of Tutoring Support within the DESS UTICEF. The tutor training is ensured by a 'super tutor' who absorbs the questions of all tutors and assists newcomers on technical and teaching axes. Training methods remain specific to each campus, and therefore quite isolated and rather ad-hoc. 
- Need for support and advice: tutors have numerous functions to fulfil for which they are little or not trained. They expressed a need for facilitation of their role through support and advice, whether this be independent of the context of the course which they monitor or within the course. We observed that tutors usually prepare their own educational content for their students (Casey et al. 2005). This point highlights an important problem: there is no tracking of their work (decisions taken, events that occur, scenario configurations or customisation, the quality of the knowledge-building process, etc.). So, there is no possibility of sharing practices and of reusing them in other contexts. During the course tutors are alone and they try to adapt their pedagogy to their students and to the progress of their learning (Casey et al. 2005). In this context it is very difficult to design an environment to assist them in their work. Furthermore, assistance tools depend on the environment, so it is quite difficult to use a same tool in various contexts. Generally recommendations, when they exist, are made by the instructional designer of the course before its commencement. Few tools answer these needs and then in a very limited way. Indeed, there are currently few assistance systems for tutors (Dufresne et al. 2003) or only specific prototypes (Garrot et al. 2006).

- Need for a professional identity: tutors have no real IT support to establish a necessary professional identity for recognition. There is one blog: $\mathrm{t} @ \mathrm{~d}$ which is a community of practice of distance tutors introduced by Jacques Rodet. Since September 2007 this has replaced a mailing list which was started in September 2004. These tools give the possibility to tutors to express their ideas and their opinions. But we consider that a mailing list or a blog are not adequate tools to establish a debate on tutors' profession and will not lead to the emergence of a recognised and official professional identity. 
In conclusion to this section, we notice that the need for (1) help in the monitoring of learners' activities and (2) the need for training are only partially answered by the existing offerings. Furthermore, there are two needs which are not yet, or only to a small degree addressed: (3) the need for support and advice to facilitate the tutors' role within the institution as well as beyond and (4) the need for recognition of tutoring as a profession and the building of a common identity. Our work tends to answer needs 2, 3 and 4 . We notice that these needs concern the local level of the institution to which a tutor belongs (facilitation of the role and the advice dependent on the course), but also a more general level common to all the tutors (training, recognition of the profession, the common identity, the advice independent from the course). In the following part, we suggest answering identified needs by considering the actors within a 'Community of Practice'.

\subsection{The concept of Community of Practice}

According to social learning theory (Brown et al. 1989), social interactions are not only sources of learning in themselves but they also oblige users to question their own experiences by comparison with those of the other users, and to make them explicit. According to this point of view, the tutor's role learning is a permanent process which forces tutors to exchange information on their practice and thereby to question it. We have leant on this hypothesis to determine the concept upon which we base our work, namely: Communities of Practice (CoP).

We aim at developing an environment to support and facilitate the development of a CoP of tutors. By defining CoPs, Wenger (1998) highlights experience and knowledge sharing between members who are: "groups of people informally bound together by shared expertise and passion for a joint enterprise". Brown and Duguid (1991) point out common practice sharing between members of 
CoPs. The concept of CoP brings us to consider tutors not only as belonging to an institution but also as a group of people developing personal practices in their work and having each different skills and experiences. Brought together in a CoP, they can exchange information about their practices and experiences by overcoming the physical or institutional boundaries (Garrot et al. 2009). With regard to the theory of CoP, the environment has the following functionalities to offer:

- A space supporting the community identity: by using a common vocabulary within the $\mathrm{CoP}$ (in our case adapted to tutoring). It is necessary to get the members to participate in the evolution of the platform in order to concurrently make the identity of the CoP evolve.

- A means to promote mutual aid and interactions between tutors: it answers the need for support and advice. To do this, it is important to facilitate the connection between members, the solving of problems, the exchange of advice, both within the institution and on a larger scale.

- A way to facilitate the development of skills and expertise: to do so the platform needs to support collaboration through the sharing of experience, analysis, debate and the creation of new methods. It also has to encourage reflexivity of the tutors in regard to their practices and lived experiences.

Our work aims at providing tutors with tools which offer long-lasting and effective help by adopting a management approach to all knowledge made explicit by tutors. It is then not only a question of managing shared resources such as documents and Web links, but also of managing all the content exchanged between tutors. Tools giving tutors the possibility to note and find experiences in their context are then necessary. Tutors must be able to find a testimony, a discussion or other resource (document, Web link) very quickly, so that they can use it or simply be inspired by it 
in their practice. The system also tries to facilitate the location of expertise which exists within the community. So, concerning the management of $\mathrm{CoP}$ knowledge, the environment allows:

- Capitalisation upon contextualised resources: it is necessary to store all the knowledge produced by the global community, whether it is the result of interactions between peers (reflections, ideas, tools) or an individual contribution (testimony, document, interesting web link). Since information only makes sense in a particular context, it is advisable to store a resource with its associated context. For example, in the case of a $\mathrm{CoP}$ of tutors, the context could be the course concerned along with an experience or a type of learner who is in trouble.

- Facilitation of the search for relevant resources: the platform has to give easy and fast access to the relevant resources for members in relation to their practice and experience. For that, an effective classification of the knowledge in regard to the community identity needs to be adopted.

This first development cycle allowed the clarification of tutors' needs through a theoretically informed interpretation of the interviews. We based the second development cycle on the requirements detailed above.

\section{Specification of the platform}

\subsection{Existing tools to support CoPs of tutors}

CoPs of tutors appear at various levels: at the local level of educational institutions and at a global level on the Web in the form of widely distributed communities of tutors from various institutions. In educational institutions tutors have many face to face exchanges in order to solve very contextual problems. For example, tutors discuss specific lessons, learners or scenarios; they give feedback on courses as a part of course development and they ask for advice and explanations on the relevant means 
of intervening with learners. But all these discussions pass unmediated by computer; they are mainly verbal and take place, for example, during coffee breaks. The knowledge so created is not or is little capitalised upon. Some CoPs are supported by web portals offered by universities (Lefoe et al. 2002, Sherer et al. 2003). These environments provide resource directories and communication tools so as to create relations between tutors of the institution and to make the CoP grow. These CoPs have already emerged independently of the technology supporting them since members already know each other or meet during meetings. These environments are not thus designed to create relations between tutors from different institutions nor to capitalise on their knowledge in a contextualised way. They are not necessary for the emergence and the life of the CoP, they only offer supplementary tools.

Web technologies (e.g. forums, blogs and wikis) have allowed the emergence of online CoPs (Pashnyak and Dennen 2007, Cuthell 2008) of tutors and teachers from different institutions. In these CoPs, tutors discuss general subjects such as answers to give to learners, the best ways to monitor and assess them, how to adapt and design learning courses, to intervene at the right time and in an adapted way and how to react effectively if a learner is in trouble. At this global level, the use of technology allows the accumulation of exchanges, but they are relatively unstructured and not contextualised. In fact, these CoPs are usually not supported by specific environments; i.e. mailing lists are mainly used to receive information without having to produce it. Blogs are mainly used to share stories, experiences and opinions and rarely to get in touch with the other persons (Pashnyak and Dennen 2007). Web tools such as blogs, mailing lists, chat and email, allow only for discussion without building concrete knowledge. Only forums bring a slightly higher degree of explicit emergence, thanks to the spatial representation they provide in the form of discussion 
threads which highlight the relations between messages. But knowledge so created is not reusable since no contextual information is assigned to it.

Numerous works aim at answering the specific needs of online CoPs by supplying tutors with tools to support specific activities. Some tools work through member participation and sociability, for example by offering a virtual 'home' like the Tapped In environment (Schlager and Fusco 2004), others by supporting collaboration between members like CoPe_it! (Karacapilidis and Tzagarakis 2007). Other tools favour the creation of contextualised resources and contextual search facilities such as the Inquiry Learning Forum (IFL) (Barab et al. 2001) and the learning environment doceNet (Brito Mírian et al. 2006). However, all these environments either favour sociability (engaging members to participate) to the detriment of the reification of the produced resources, or they favour the accumulation and indexation of contextualised resources, but to the detriment of sociability and member participation. There are some new approaches which try to adapt a more Web 2.0 type approach to sharing and networking, for example the Cloudworks system (Conole et al. 2008). But these environments are not designed to simultaneously support CoPs' activities both in the local context of members' practice (i.e. their own schools, educational departments or institutions) and at the global level of a widely distributed community in various institutions.

To sum up, none of the studied environments and tools offers the five functionalities identified as needed for an environment to support a CoP (cf. $\S 3.3$ ). Some technologies do not support online CoPs but only facilitate the communication of existing face-to-face CoPs. Other tools favour either sociability to engage members to participate, to the detriment of the capitalisation of the produced resources, or the capitalisation of contextualised resources and the facilitation of their search, to the 
detriment of sociability and members' participation. In this context, the aim of the second development cycle is to develop a platform which can support all the defined requirements.

\subsection{Steps of the second development cycle}

For the two next cycles, we adopt the evolutionary approach (Floyd 1993, Muller 2003) and develop for each cycle a new prototype of a system that is delivered to the end users. At each cycle, we make the functionalities of the system evolve according to the evolution of users' needs as they integrate the system into their practice. At the same time, from the first prototype onwards we make the vocabulary of the interface evolve by its use in the system through what has been termed 'co-adaptive conception' (Mackay and Fayard 1997). The aim of the experiment is to spark off users' reactions by using the prototype and to observe their practice. It allows the typology of users' needs to be evolved and become more precise and more complete. The different steps are:

a. The development of a prototype proposing a simple interface and a few functionalities. We want to develop an innovative system which will respond to needs which do not exist or could not emerge easily. That is why this step does not have to be too long, the purpose being not to develop the final system but rather to observe users' reactions.

b. The use by the users of the developed environment. This step causes users to express their needs in terms of functionalities and tools as they go through the process of the integration of the system into their practice.

c. The analysis of two types of information based on the results from the previous step (b). 
- Traces of use (system logs): quantitative information on the use of the environment (e.g. frequency, functionalities used)

- Questionnaire results: qualitative information on the opinion of the users about the environment (e.g. missing functionalities, interface problems)

The analysis can be made with regard to existing theories on user activities. Research can help to explain user behaviour and their use of the proposed environment, in relation to their purpose when achieving their task. By drawing on relation theories, questionnaire results and traces of use of the environment, we can refine the field of users' needs.

\subsection{Illustration with TE-Cap}

At this stage, we initiated the prototype by giving it a name: TE-Cap (Tutoring Experience Capitalisation) (Garrot et al. 2007). We based the development of the TECap environment on the needs identified in the first development cycle. The conception of the platform TE-Cap relies on the CMS (Content Management System) open source Joomla!. We opted for this CMS according to some criteria and from among a comprehensive list of existing CMS1. The main reasons for this choice are, on the one hand, that it proposes basic functionalities which thus do not need to be developed again (such as articles, documents and user management) and, on the other hand, that its functionalities are based on independent components so the evolution capacities and the modularity of TE-Cap is largely facilitated. We modified some components and developed others so as to answer needs previously identified.

\subsubsection{TE-Cap functionalities}

1) Perception and sharing among community members: the environment displays the list of tutors who belong to the community. It is possible for each member to

\footnotetext{
${ }^{1} \mathrm{http}: / / \mathrm{cmsmatrix} . o r g /$
} 
consult these profiles and to send to another a personal e-mail directly from the interface. In this way, a novice tutor in a domain of skill (technical or educational skills or skills concerning particular content) can ask directly for help from a more expert tutor in this domain. The visualisation of member profiles brings conviviality and awareness to the site, inciting the members to participate in the community life.

2) Personal space within the community portal: by connecting to the platform the tutor can display messages, documents and Web links which s/he proposes to the community, which are displayed along with an indication of the number of times they have been viewed by other tutors (see Figure 3). They can also consult the comments made on a message. Tutors have the choice whether or not to diffuse the messages they write. This functionality plays the role of a log book which can contain private and public parts. Furthermore, before validating a message tutors have to specify their intention as: 'testimony', 'discussion' or 'request for help'. This constrains tutors to reflect upon their intention and creates a first classification of messages. Before sending a message thus, tutors have to classify it with a dedicated interface which is presented in the next section (see Figure 4).

\section{Figure 3}

3) Knowledge capitalisation: to meet the need for management of all knowledge produced by the community (see $\S 4.2 .2$ ), we developed a component of knowledge classification, integrated in the CMS. The classification is based on the model of the factors in relation with a practice of tutoring developed as a result of the first development cycle (see $§ 3.2 .2 .1$ ). It uses a vocabulary adapted to the community. The classification appears in the form of a dynamic tree structure (see Figure 4). This component offers two main functionalities: 
- When tutors send a message, a document or a Web link, they have to choose the corresponding subjects in the dynamic tree structure. For example, if tutors ask for help because they do not know how to react in front of a learner in trouble within a workgroup, they can check the box 'In trouble' under the subject heading 'Position inside the group' in the part classed as 'Concerned learners' (see Figure 4).

- Tutors can look for all the types of resources relating to one or several subjects in relation to tutoring. If they find an interesting resource, they can consult it and add it to their favourites. Furthermore, they can choose to react to a message, to offer assistance or to pursue a discussion for instance.

\section{Figure 4}

The classification tool is at the heart of our proposed design framework and allows a co-adaptive conception of the environment. Tutors can make the initial classification evolve by proposing new categories. These new categories are proposed to the moderator of the community who decides to add them or not. Furthermore, the categories used by tutors are recorded which allows, for example, to identify little or unused ones.

If we refer to the requirements based on the theory of $\mathrm{CoP}(\mathrm{see} \S 4.2 .2)$, this functioning allows tutors to use a vocabulary common to the CoP, to make the members participate in the evolution of the environment and also to encourage the reflexivity of tutors regarding their practices, since they have to think about categories which are the best suited to the experience they have just written about. This approach offers the possibility to tutors of adopting the environment for themselves which is essential if we want them to use it. 


\subsubsection{Analysis of the results of the pilot study}

The study of the prototype involved the participation of twelve tutors from six countries: Costa Rica, Senegal, Algeria, France, Tunisia and Canada. Since “communities are emergent" (Brown and Duguid 1991), we can not 'create' a CoP. That is why we asked some tutors who belong to an existing CoP of tutors (named $\mathrm{t} @ \mathrm{~d})$ to test the environment. These tutors are from different institutions and disciplines (e.g. educational science, computer science, mathematics, pedagogy, project management). They used the prototype TE-Cap during a two month period and tried to integrate it into their practice.

We have defined criteria to observe the response of this prototype to tutors' needs. These criteria are: usability and sociability of the environment (Preece 2001) as well as the measurement of the volume of creating and sharing knowledge activity (Koh and Kim 2004). These criteria are measured from tracks of the use of the environment which are stored during the progress of the test and then manually analysed. The answers to a questionnaire addressed to tutors at the end of the trial give qualitative subjective information about the opinions of the users of the platform (e.g. missing features, problems of interface). Unfortunately, we had only five questionnaires (out of twelve) returned to us, which were not completely filled out at that. The interpretation of the results with regard to the properties of communities of practice gives more information to determine the functionalities for a final platform.

With regard to usability, we have, in particular, obtained results on answering to the need for communication between members. The first result is that there were fewer interactions than we supposed: only thirteen messages were posted (including seven from the administrator) and there was an average of three answers per posted message ( 36 messages in all). There were only two emails sent by the environment (to the administrator), although there were eighteen accesses to the interface of email 
sending. Moreover, tutors wrote in the questionnaires that they hadn't had any contact with other members apart from in the environment (no contact through emailing each other). They however declared that the means of communication are sufficient and well adapted.

We also wanted to obtain information on the ease of use (ease of reading, understanding and navigation), the efficiency and the functioning of the environment but we did not have enough returns of questionnaires to determine significant results. Those tutors who did answer the questionnaire considered these criteria as good or rather good. Other functionalities which they said they would have liked to have were a synthetic dashboard showing the latest novelties and an agenda with postings of the most recent events without needing to look for them. Concerning the actual functioning of the environment, no technical problems or bugs occurred.

Concerning sociability, tutors said they had felt a sense of membership of the community and that they were comfortable within that community. But there was no emergence of roles and tutors estimated their engagement (participation) in the community as being on a mean level. With regard to the message quality, we see that there are very interesting discussions and that when the subject concerns everybody, there are many reactions. For instance, there were five answers to a message concerning the easy fall in in-class activities every time there are problems in the progress of distance learning. The whole discussion was very interesting. For a request for help on: 'how to help learners to manage their time better?', we also observed answers which are very constructive. We thus see that when tutors exchanged information within the environment, it was always in a very serious and interesting way. Our purpose to favour exchanges traversing the frontiers of institutions was realised, even if the exchanges were not many. 
In regard to creating and sharing knowledge activities, we observe that there were not many resources proposed by tutors. As described above, there were only 36 messages posted. Furthermore, there were only two documents uploaded and no Web links. A possible explanation for these observations is that the distinction between three types of resources is not coherent. Indeed, one tutor wrote on a questionnaire that "the distinction between these three types of doc is impossible for me: an article is a document, and behind a link we have a document, which can be an article! I do not understand what can be of use in this distinction." This could explain the lack of use of the functionalities of documents and Web links submission.

We observe that only 18 searches have been made by only three users. The two documents posted by users were downloaded respectively only one and three times. The discussion threads were shown on average 34 times. There were 79 profile visualisations, but, as declared in the questionnaires, not to look for an expert but more out of curiosity. Concerning the interface for search, eight categories were used (among those proposed in the hierarchical classification) and seven were proposed. For the classification, twenty categories were used for messages and eight for documents. Only two categories were proposed. So we suppose that tutors did not take the time to find the categories which corresponded best to their message giving an account of an experience or to search interesting resources. They did not spend time on thinking about other categories than those which are proposed.

We make four hypotheses to explain all these results:

- There were not enough members in the community (twelve tutors) to generate high levels of interactions between tutors. It implies that there is a minimal size required for the community to engender the emergence of rich interactions. 
Furthermore, all the tutors were from different institutions so they could not exchange about concrete problems which they encounter in their day to day practice. We think that it is from the sharing of these very contextual concerns that wider and more global exchanges in a $\mathrm{CoP}$ of tutors can arise. In the next experiment we shall invite tutors of same institutions to participate so that there is this first level of exchanges.

- Tutors prefer to receive the information rather than to have to connect to the environment to see new messages, new comments or new documents. So we propose to add notification of information by integrating the technology of syndication feed (RSS) into the environment.

- The usability of the interface we have developed to classify and search resources is not well adapted to tutors. The presentation of the classification in the form of a dynamic tree structure has to be modified and improved.

- In regard to the theory of CoP developed by Wenger (1998), we think we have prioritised the reification of knowledge over the participation of the community. We have developed a tool to manage the resources produced by the community but we have not proposed enough possibilities to access these resources easily and to react to them. For example, the tutor has to search for messages which have been posted so as to respond to them. Furthermore, it is not possible to react to a proposed document or to a Web link. So the link between reification and communication was not emphasised enough in this first prototype. This is one of the most important points we have to take into consideration as we make the environment from the next cycle evolve. 


\subsubsection{Discussion}

We do not question the utility of the test in spite of the minimal use of the system observed. The prototype is designed to support very diverse and emergent tasks which are impossible to evaluate by usability tests alone. Only tests in real life situations can allow conclusions to be drawn on the users' activities. This study highlights two critical points of our approach:

- The duration of the test: CoPs evolve slowly (Lave and Wenger 1991) and it is very difficult to lead persons who do not know each other to engage together in a $\mathrm{CoP}$ of a short duration. That is why results allowing any estimations of the success of the community and of the platform can be obtained only at the end of a long period of use. The community environment becomes beneficial in the long term and with a large number of users. This problem is generalisable and applies to the design of any innovative software: it is very difficult to anticipate the activity of the users with software which does not still exist or which does not present an equivalent (Delozanne et al. 2002). This problem is very difficult to overcome in a co-adaptive approach, since artefacts are no more than propositions which the individuals will adopt or not. If the prototype does not answer direct needs, users are not going to use it.

- The community members: we wanted to test how the prototype answered to the needs of a community in terms of IT support, hoping that a community would appear from members belonging to existing CoPs bound to tutoring. However, the global community did not appear and apparently no relations were created between the members. This can be explained by the fact that tutoring is very often a supplementary activity which the tutors have besides their main job. Their main job being of priority, the tutors do not have much time to devote to learn to use a new tool. Furthermore, the lack of recognition for their profession may mean that 
they do not perhaps want to devote more time than that for which they are paid. Finally, tutoring being a rather individualistic activity, the tutors possibly do not want to share what they have taken time to build on their own. We suppose that the results of the study would have been different if we had addressed an already existing global community, reactive and accustomed to exchange.

The following development cycle is based on the analysis of the results presented previously, interpreted by means of the properties of CoPs. It is based on the hypothesis that it is from the sharing of very contextual subjects that wider and more global exchanges in a CoP of tutors can appear. The interactions have to be initiated at a local level (the course or the institution) to rise then to a global level (beyond institutions) to come down again to a local level (in another institution or courses). Furthermore, we do not consider the tutors as a single CoP any more, but rather as a set of interconnected CoPs. That is why we developed a new model of Interconnection of CoPs which reflects the reality of the interactions observed during the test (Garrot-Lavoué 2009).

\section{Adequacy of the platform for users' activities}

This third cycle is based on the precise user needs and expectations identified in the two first cycles. It is also based on the model of Interconnection of CoPs developed as a result of the second development cycle. It allows the development of an environment which proposes adapted functionalities to the users. Furthermore, the interface development is based on the vocabulary used by users during the interviews and the classification which has evolved during the second development cycle. We have demonstrated the importance of this point for the users to use the environment. The steps of this third cycle are the following: 
a. Modification and improvement of the prototype developed in the second development cycle to respond exactly to users' needs. This step should be carried out with the participation of the users of the first prototype, in order to incorporate their advice during the development. So it consists of:

- Making the vocabulary used for the interface evolve.

- Modifying, adding or deleting functionalities.

- Structuring the presentation of information on the interface.

b. Use of the environment by the users. The environment must be equipped with an adapted tracking tool to enable the analysis of the use of the environment by the users. It is too complex (and generally not possible) to give another questionnaire to be filled out by users.

c. Analysis of traces of system use. In this step we have to refer to the typology and to compare for each need the degree of response by the system. If the difference between needs and the response is too high, it is necessary to carry out another development cycle, again with the participation of the users.

This third cycle is integrated in our global design approach for an assistance environment for tutors. If the platform does not respond enough to users' needs, we will return to the second cycle in order to improve the adequacy of the environment. The application of this third cycle is explained in (Garrot-Lavoué 2009).

\section{Conclusion and future directions}

In this paper we develop a co-adaptive design approach composed of three cycles, which aims at developing a system for users who do not have well identified tasks and needs. Each cycle rests on the development of a prototype based on theory as well as on the identification of users' needs and expectations. We detail the process used to 
obtain the specifications of the final platform, by observing the use of prototypes by users and analysing them in regard to theories on user activities.

By illustrating our approach with the development of an assistance environment for tutors we showed that it is difficult to involve users in the participatory process. The pilot study of the first prototype was not as successful as we had supposed because tutors did not interact a lot inside the environment. In this paper, we have discussed the reasons which can explain this low activity, principally the too short duration of the test and the type of community concerned. Nevertheless, the first two cycles have brought important information to the conception of the final TE-Cap platform.

The third cycle is based on a general model of Interconnection of Communities of Practice (ICP). This model proposes to consider a group of actors practicing a same activity as a set of CoPs supported by a Web platform where individual members act as nodes of interconnected practices and are the connection points (Garrot-Lavoué 2009). This model is based on the concept of Constellation of CoPs developed by Wenger (1998) and on the assumption that considering a global community as a set of interconnected CoPs will increase member participation and creation of knowledge. This proposition of an ICP model aims at making existing local CoPs of actors (e.g. within an educational institution), who are engaging in the same general activity (e.g. tutoring), to get connected. This model also proposes active support for the dissemination of knowledge from CoP to CoP.

The model of ICP was implemented and has been used to develop the TE-Cap 2 platform (Garrot-Lavoué 2009) which has, as its field of application, educational tutoring activities. In particular, we propose an indexation and search tool for the ICP knowledge base. The TE-Cap 2 platform has been used in a real situation. 


\section{References}

Barab, S., MaKinster, J., Moore, J., Cunningham, D., and ILF Design Team. Designing and building an online community: The struggle to support sociability in the Inquiry Learning Forum. Educational Technology Research and Development, 2001, 49 (4), 71-96.

Brito Mírian, C.A., da Nóbrega, G.M. and de Oliveira, K.M. Integrating Instructional Material and Teaching Experience into a Teachers Collaborative Learning Environment. In: First European Conference on Technology Enhanced Learning (EC-TEL 2006). Crete, Greece : Springer Berlin / Heidelberg, 2006, 458-463.

Brown, J.S. and Duguid, P., 1991. Organizational learning and communities of practice. Organization Science, 2(1), 40-57.

Brown, J.S., Collins, A. and Duguid, P., 1989. Situated Cognition and the Culture of Learning. Educational Researcher, 18(1), 32-42.

Casey, J., Brosnan, K. and Greller, W., 2005. Prospects for using learning objects and learning design as staff development tools in higher education. In Proceedings of the IADIS International Conference on Cognition and Exploratory Learning in Digital Age (CELDA 2005), Porto, Portugal, 14-16 December, 96-104.

Class, B. and Schneider, D., 2004. Tutorat, socio-constructivisme et capitalisation des connaissances dans un portail communautaire utilisé en éducation à distance [online]. In Proceedings of Eifad (École d'Ingénierie de la Formation à Distance) Symposium, Poitiers, France. Available from: http://www.cned.fr/colloqueeifad/Documents/Class_Schneider.pdf [Accessed 25 September 2007]

Conole, G., Culver, J., Williams, P., Cross, S., Clark, P. and Brasher, A. Cloudworks: Social networking for learning design. In: Ascilite 2008 Conference. Melbourne, 2008, 187-196.

Cuthell, J.P. The role of a web-based community in teacher professional development. International Journal of Web Based Communities , 2008, 4 (2), 115-139.

Delozanne, É., Grugeon, B. and Jacoboni, P., 2002. Analyses de l'activité et IHM pour l'éducation. In Proceedings of the 14th International Conference on Interaction Homme Machine (IHM 2002), Poitiers, France, ACM Press, November, 25-32.

Després, C., 2003. Synchronous Tutoring in Distance Learning. In Proceedings of the 11th International Conference on Artificial Intelligence in Education (AIED 2003), Sydney, Australia, IOS Press, 20-24 July, 271-278.

Dufresne, A., Basque, J., Paquette, G., Léonard, M., Lundgren-Cayrol, K. and Prom Tep, S. Vers un modèle générique d'assistance aux acteurs du téléapprentissage. Revue STICEF, 2003, 10, 57-88.

Floyd, C., 1993. STEPS - A methodical approach to PD. Communications of the ACM, ACM Press, 36(3), 83.

Galanouli, D., Murphy, C. and Gardner, J., 2004. Teachers' Perceptions of the Effectiveness of ICT-Competence Training. Computers and Education, 43(1-2), 63-79.

Garrot, E., George S. and Prévôt, P., 2006. A system to support tutors in adapting distance learning situations to students. In Proceedings of the 2nd International Conference on Web Information Systems (WEBIST 2006), Setúbal, Portugal, 19-22 April, 261-267.

Garrot, E., George, S. and Prévôt, P., 2007. The Development of TE-Cap: an Assistance Environment for Online Tutors. In Proceedings of the 2nd European Conference on Technology Enhanced Learning (EC-TEL 2007), Springer LNCS, 481-486.

Garrot, E., George, S. and Prévôt, P. Supporting a Virtual Community of Tutors in Experience Capitalizing. International Journal of Web Based Communities, 2009, 5(3), 407-427.

Garrot-Lavoué, E. Interconnection of Communities of Practice: a Web Platform for Knowledge Management. In: International Conference on Knowledge Management and Information Sharing. Madeira, Portugal, 2009, in press.

George, S., 2006. Bridging the Gap Between Human Communications and Distance Learning Activities. In: Eshaa M. Alkhalifa, Cognitively Informed Systems: Utilizing Practical Approaches to Enrich Information Presentation and Transfer. Idea Group Publishing, 102-116.

Godinet, H. and Caron, C., 2003. L'accompagnement du processus d'apprentissage dans le Campus Numérique FORSE : modalités et outils. In Proceedings of the Conference on Environnements Informatiques pour l'Apprentissage Humain (EIAH 2003), Strasbourg, France, 15-17 April, 223-234.

Holtzblatt, K. and Beyer, H., 1993. Making customer-centered design work for teams. Communications of the $A C M$, ACM Press, 36(3), 92-103.

Jarke, M., 1999. Scenarios for modeling. Communications of the ACM, ACM Press, 1999, 42(1), 47-48.

Karacapilidis, N. and Tzagarakis, M. Web-based collaboration and decision making support: A multi-disciplinary approach. International Journal of Web-Based Learning and Teaching Technologies, 2007, 2 (4), 12-23.

Koh, J. and Kim, Y.G., 2004. Knowledge sharing in virtual communities: an e-business perspective. Expert Systems with Applications, 26(2), 155-166.

Kuhn, S. and Muller, M. J., 1993. Participatory design. Communications of the ACM, ACM Press, 36(4), 24-28.

Laperrousaz C., Leroux P. and Teutsch P., 2005. Analyzing a collaborative writing activity in order to improve tutor's perception of individual contributions of learners. In Proceedings of the IEEE International Conference on Advanced Learning Technologies (ICALT 05), Kaohsiung, Taiwan, 5-8 July, 182-184.

Lave, J. and Wenger, E. Situated Learning. Legitimate Peripheral Participation. Cambridge, UK: Cambridge University Press, 1991, p.138.

Lefoe, G., Hedberg, J. and Gunn, C. The Changing Role of Tutors: Forming a Community of Practice in a Distributed Learning Environment. In: International Conference on Computers in Education (ICCE'02). 2002, 729-733. 
Mackay, W.E. and Fayard, A-L., 1997. HCI, Natural Science and Design: A Framework for Triangulation Across Disciplines. In Proceedings of ACM Conference on Designing Interactive Systems (DIS 1997), Amsterdam, 223-234.

McPherson, M. and Nunes, M. B., 2004. The role of tutors as an integral part of online learning support [online]. European Journal of Open, Distance and E-Learning (EURODL), 1. Available from: www.eurodl.org/materials/contrib/2004/Maggie MsP [Accessed 25 September 2007].

Muller, M., 2003. Participatory Design: the third space in HCI. In: Jacko J., and Sears A., The Human Computer Interaction Handbook, Lawrence Erlbaum.

Pashnyak, T.G. and Dennen, V.P. What and Why do Classroom Teachers Blog? In: IADIS Web Based Communities Conference. Salamanca, Spain, 2007, 172-178.

Preece, J., 2001. Sociability and usability in online communities: Determining and measuring success. Behaviour and Information Technology, 20(5), 347-356.

Schlager, M. and Fusco, J. Teacher professional development, technology, and communities of practice: Are we putting the cart before the horse? In: Designing for virtual communities in the service of learning. Cambridge, UK : Cambridge University Press, Barab, S., Kling, R. and J. Gray (Eds.), 2004, 120-153.

Sherer, P.D., Shea, T.P. and Kristensen, E. Online Communities of Practice: A Catalyst for Faculty Development. Innovative Higher Education, 2003, 27 (3), 183-194.

Song, K.-S., Hu, X., Olney, A. and Graesser, A.C., 2004. A Framework of Synthesizing Tutoring Conversation Capability with Web-Based Distance Education Courseware. Computers and Education, 42(4), 375-388.

Stahl, G., Rohde, M. and Wulf, V., 2007. Computer support for learning communities. Behaviour and Information Technology, 26(1), 1-3.

Wenger, E., 1998. Communities of practice: Learning, meaning, and identity. Cambridge, Cambridge University Press.

West, R. E., Waddoups, G. and Graham, C. R., 2007. Understanding the experiences of instructors as they adopt a course management system. Educational Technology Research and Development, 55, Springer, Boston, 1-26.

Wood, L. E., 1997. Semi-structured interviewing for user-centered design interactions. Interactions, ACM Press, $4(2), 48-61$. 
Figure 1. An experimental co-adaptive design approach

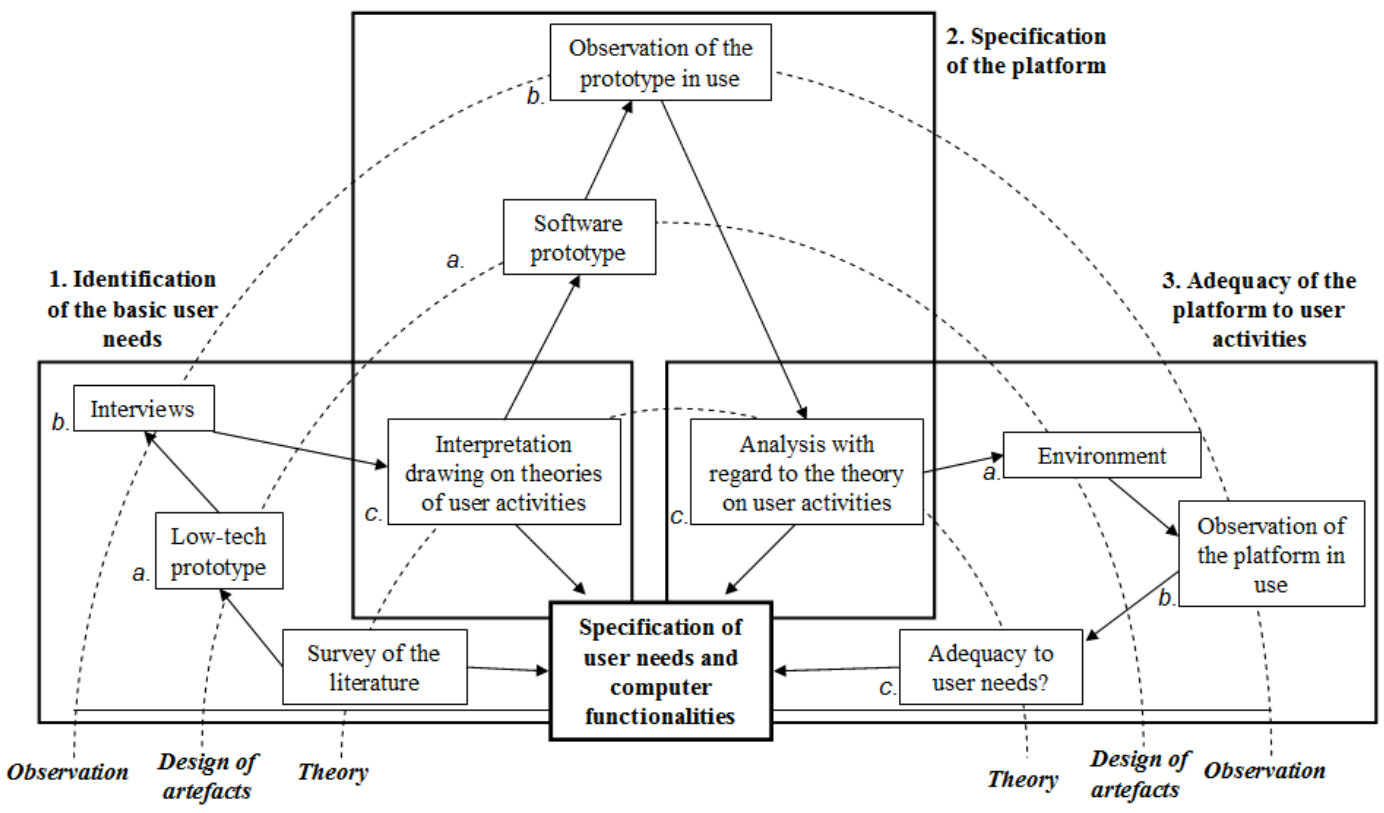


Figure 2. The design of the early interface: experience Matrix per function per phase.

\begin{tabular}{|c|c|c|c|c|c|}
\hline & & & ases of probl & olving activi & \\
\hline & & $\begin{array}{c}\text { Problem } \\
\text { formalization }\end{array}$ & $\begin{array}{l}\text { Cause } \\
\text { searching }\end{array}$ & $\begin{array}{l}\text { Solution } \\
\text { proposition }\end{array}$ & $\begin{array}{c}\text { Solution } \\
\text { implementation }\end{array}$ \\
\hline & & 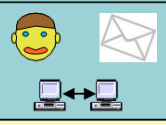 & 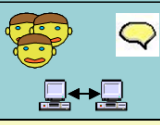 & $\begin{array}{l}\Leftrightarrow A \\
\square \leftrightarrow \square\end{array}$ & 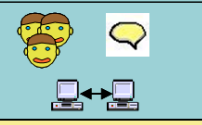 \\
\hline & Assessor & 1 & 2 & 3 & 5 \\
\hline & Intellectual catalyst & 11 & 4 & 1 & 6 \\
\hline & Interaction moderator & 5 & 7 & 0 & 0 \\
\hline futor & Motivational support & 2 & 6 & 7 & 3 \\
\hline & Learning regulator & 5 & 10 & 4 & 0 \\
\hline & Technical support & 8 & 4 & 1 & 2 \\
\hline & Pedagogical architect & 1 & 5 & 0 & 0 \\
\hline
\end{tabular}


Figure 3. The personal homepage provided to each user.

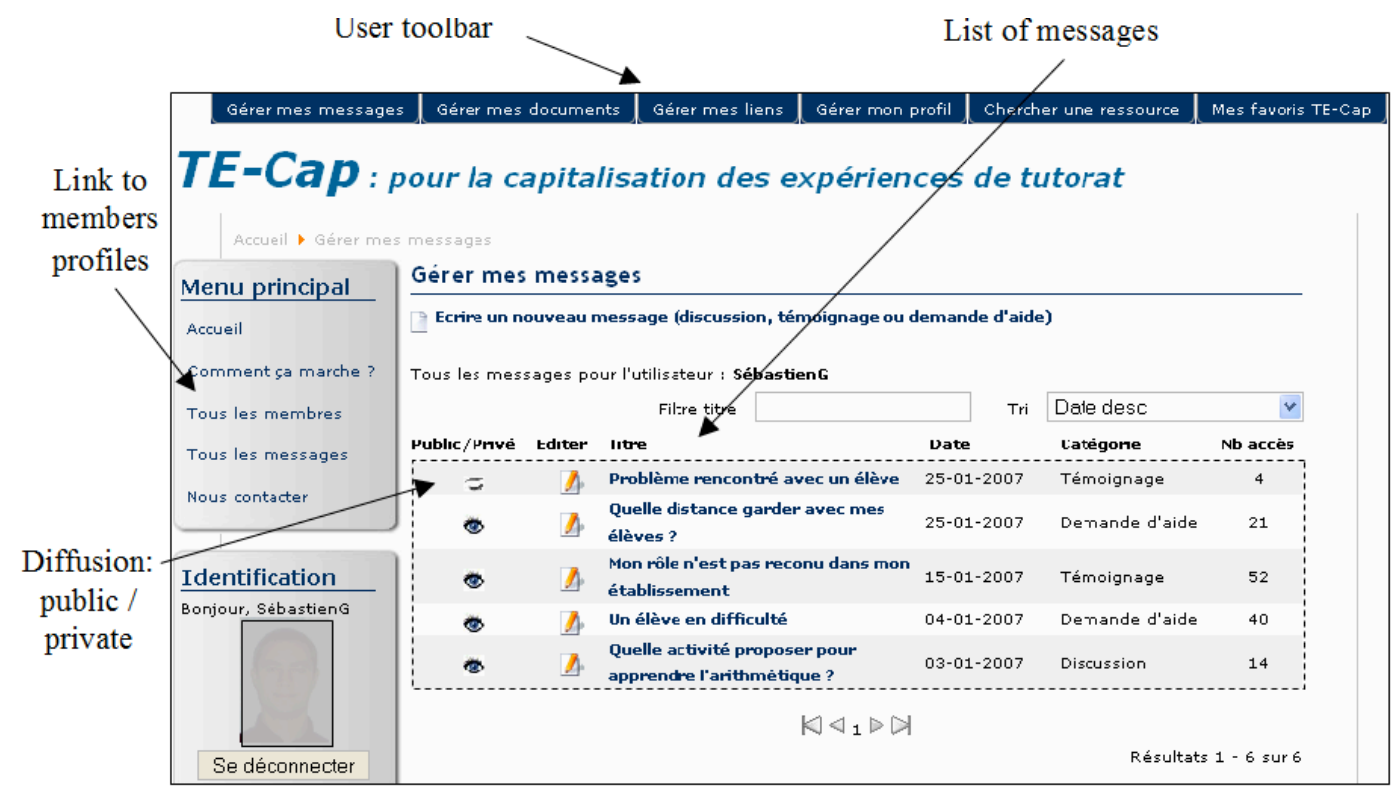


Figure 4. Interface for classification and search for resources.

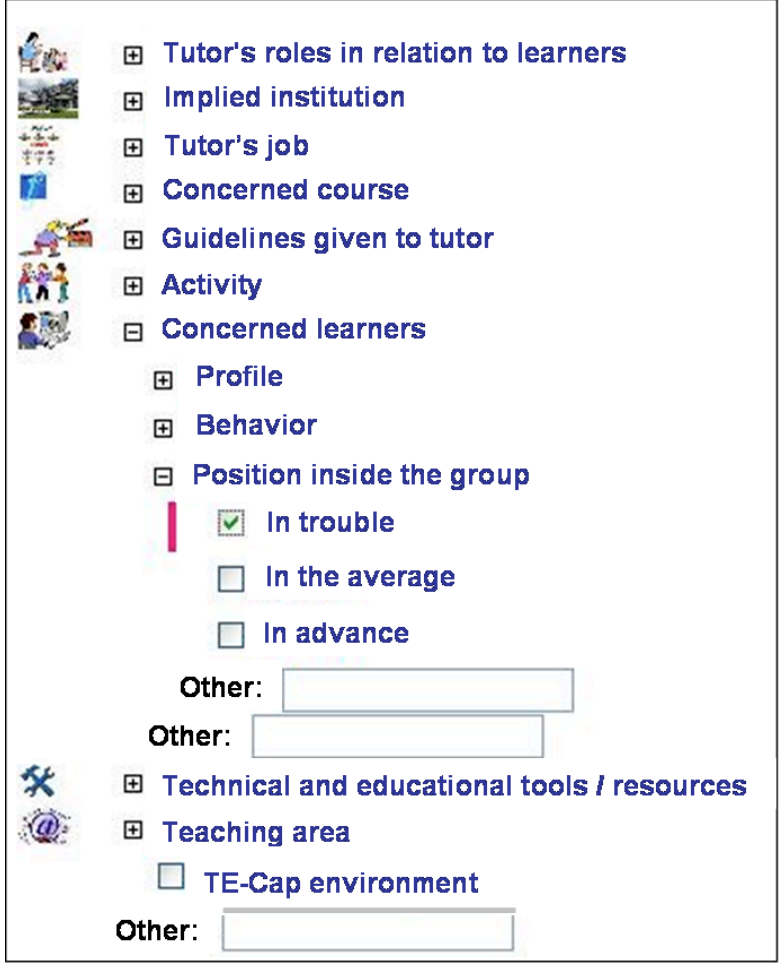

